\title{
O mapa brasileiro da pesquisa experimental em Comunicação
}

\author{
José Marques de Melo*
}

\section{Resumo}

O desenvolvimento da pesquisa experimental em Comunicação alcançou estágio significativo no Brasil, integrando o trabalho didático ao ensaio laboratorial. O artigo objetiva resgatar e analisar, com base em análise documental sobre os indicadores da pesquisa experimental e os resultados dos trabalhos ganhadores do Prêmio EXPOCOM 2011, o percurso desse tipo de experimentação e o papel da INTERCOM na dinamização dessa atividade no Brasil. Conclui-se que o enigma persistente está na aferição da qualidade dos trabalhos premiados, de modo a indicar em que medida eles constituem mera reprodução do que pratica o mercado ou são experimentos inovadores.

Palavras-chave: Ciências da Comunicação. Pesquisa experimental. Brasil. INTERCOM. EXPOCOM.

\section{El mapa brasileño de la investigación experimental en comunicación Resumen}

El desarrollo de la investigación experimental de la comunicación se ubicó, en Brasil, principalmente en las Carreras de licenciatura, como soporte didatico o estrategia metodológica. Este artículo tiene como objetivo recuperar y analizar, con base en el análisis documental de la investigación sobre los indicadores y los resultados del trabajo experimental ganadores EXPOCOM de 2011, la ruta de este tipo de experimentación y el papel de INTERCOM en el fomento de esta actividad en Brasil. Llegamos a la conclusión de que la clave está en la calidad de los trabajos ganadores, en qué medida ellos son copia del mercado o experiencias innovadoras.

Palabras clave: Ciencias de la comunicación. Investigación experimental. Brasil. INTERCOM. EXPOCOM.

\footnotetext{
* Professor titular do Programa de Pós-Graduação em Comunicação Social, Faculdade de Comunicação da Universidade Metodista de São Paulo, São Bernardo do Campo- SP, Brasil, onde é diretor da Cátedra UNESCO de Comunicação. Preside o Conselho Curador da INTERCOM. Doutor e livre-docente em Ciências da Comunicação - Jornalismo pela Universidade de São Paulo, Brasil, publicou meia centena de livros e coletâneas e mais de uma centena de artigos em periódicos científicos do país e do exterior. E-mail: marquesmelo@uol.com.br
} 


\section{Brazilian map of experimental communication research Abstract}

Experimental research projects are a relevant metodological tool used by Communication Schools in Brazil at the undergraduate level. This article aims to rescue and discuss, based on documentary analysis of research on indicators and results of experimental work EXPOCOM winners of 2011, the route of this type of experimentation and the role of INTERCOM in stimulating this activity in Brazil. We conclude that the key is in the quality of the winners, to indicate to what are merely copy the market or what practices are innovative experiments.

Keywords: Communication scholarship. Experimental research. Brazil. INTERCOM. EXPOCOM.

\section{Empiria, experimentação}

pesquisa experimental constitui-se, segundo Duverger (1962,
p.99), como uma experiência "provocada e controlada",
gerando saber utilitário. Esse conhecimento é produzido por pesquisadores que "observam" de forma rigorosa e sistemática os fenômenos, submetendo seus relatos ao julgamento dos pares, na especialidade, com a intenção de validá-los corporativamente.

No campo da Comunicação, a natureza da pesquisa experimental foi previamente descrita por Marques de Melo (1970, p.98) como "experiências controladas, em grupos de receptores ou em mercados-piloto, com a finalidade de testar mensagens ou avaliar o impacto de canais". A seguir, seleciona algumas das experiências relevantes. "É o estudo de um novo jornal ou revista, cuja edição zero se distribui a uma amostra de leitores em potencial, que apresentam críticas e sugestões depois de efetuar a leitura. É o estudo de um novo programa de televisão, exibido em circuito fechado a um grupo especial de telespectadores, que emitem opiniões, ou apresentam reações determinadas".

A quem interessa esse tipo de pesquisa? Principalmente aos tomadores de decisão nos processos comunicacionais, que delas se valem para fazer investimentos, orientar planejamento, supervisionar recursos humanos, mas também para treinar os futuros profissionais da área.

No Brasil, o universo da pesquisa orientada para experimentar produtos, campanhas e veículos desenvolveu-se fora das muralhas 
universitárias, contrastando com a matriz norte-americana, na qual esse filão investigativo nasceu dentro do próprio campus. A metodologia para aferição da audiência da mídia eletrônica está enraizada na tese de doutorado que Georges Gallup defendeu na Universidade de Iowa, nos anos 30, sendo posteriormente importada pelo fundador do IBOPE, Auricélio Penteado, que a adaptou para a realidade brasileira. Hoje, existem no país dezenas de empresas que realizam pesquisas dessa natureza, prestando serviços aos gestores midiáticos.

$\mathrm{O}$ interesse da academia pela pesquisa experimental remonta aos anos 80, quando os órgãos federais de fomento ao ensino superior instituem a obrigatoriedade dos equipamentos didáticos nos cursos de Comunicação. Vivíamos uma conjuntura marcada pela tecnofobia e pelo teoricismo. "Apesar da hegemonia então exercida pelos adversários do empirismo, a força da lei atuou no sentido de estruturar atividades de ensino comprometidas com a aplicação prática dos conhecimentos assimilados pelos jovens na sala de aula" (MARQUES DE MELO, 2008b, p.76).

$\mathrm{O}$ crescimento e a sedimentação desse tipo de pesquisa foram em grande parte amparados e fomentados pela INTERCOM, ao criar um espaço próprio para a experimentação comunicacional, denominado EXPOCOM.

Passadas duas décadas, a configuração da nossa comunidade acadêmica se tornou diversificada, contribuindo para neutralizar preconceitos. Tanto assim que as duas principais sociedades científicas do campo da Comunicação pautaram a pesquisa empírica como tema principal dos seus congressos anuais: COMPÓS (BRAGA; LOPES; MARTINO, 2010) e INTERCOM (BARBOSA; MORAES, 2011).

Mas a problemática ainda suscita inquietações, como por exemplo, aquelas sinalizadas por Antonio Hohlfeldt (2011) ao questionar se a pesquisa empírica é possível num país com tradição escravista. Ou por Regina Rosetti (2010), advertindo que a inovação na pesquisa em Comunicação depende de uma ruptura epistemológica com o "empirismo ingênuo". Ou por Raquel Paiva (2011), indagando, com implícito ceticismo, se há "lugar para a empiria” na pesquisa da Comunicação comunitária. Talvez por 
isso mesmo, Marialva Barbosa (2011b) tenha se antecipado, ao proclamar: "não precisamos ter mais medo do contágio".

Por isso, achei imprescindível contextualizar esta narrativa, situando-a institucionalmente, na expectativa de esclarecer os leitores mais jovens.

\section{Estímulo à pesquisa}

A Sociedade Brasileira de Estudos Interdisciplinares da Comunicação - INTERCOM - vem se consolidando como a organização não-governamental que reúne a maior comunidade acadêmica do campo comunicacional, na América Latina. Tem fomentado o balanço das tendências da pesquisa científica nessa área do conhecimento, há 34 anos, em nosso país. Para tanto, abriu espaço privilegiado, em seu congresso anual, à apresentação e ao debate dos estudos realizados pelos pesquisadores atuantes nas universidades, empresas, órgãos públicos e movimentos sociais.

Durante os primeiros anos, a INTERCOM privilegiou os estudos convencionais (empíricos ou teóricos), oriundos dos projetos individuais de doutorado, mestrado ou iniciação científica. Mas, no início da década dos 90, a diretoria tomou a iniciativa de estimular a pesquisa experimental desenvolvida nos cursos de graduação, incluindo os trabalhos laboratoriais feitos durante a formação profissional e os projetos de conclusão de curso (experimentais ou monográficos).

Essa ofensiva decorreu do alerta feito por pesquisadores que atuam em duas frentes simultâneas, no mercado e na academia, temerosos da esclerose precoce de instituições que operam distanciadas da realidade. Nilson Laje, por exemplo, em palestra proferida no II Simpósio da Pesquisa em Comunicação da região Sul (Curitiba, 1992), advertia para o equívoco da "velha tese": "é melhor importar do que produzir". Concitando as novas gerações a "mudar radicalmente de rumo", ele apontava o caminho: "admitir e respeitar as especificidades das práticas de Comunicação no ensino e na pesquisa" (Revista Brasileira de Ciências da Comunicação, v. XVI, v. 1, São Paulo, INTERCOM, 1992, p.168).

Nessa conjuntura, foi instituída a jornada anual que valorizou a pesquisa experimental em Comunicação, mobilizando os estu- 
dantes e professores da graduação no espaço que veio a se firmar como EXPOCOM.

\section{Pesquisa aplicada}

A primeira EXPOCOM foi realizada como evento integrante da programação do XVIII Congresso Brasileiro de Ciências da Comunicação, sob a liderança do Prof. Paulo Rogério Tarsitano, que esteve em sua coordenação pedagógica durante vários anos. Ele a tomou como objeto de pesquisa, valendo-se do método da observação participante. Dessa investigação, resultou a tese de doutorado, defendida em 1999 na Universidade Metodista de São Paulo, sob o título "A EXPOCOM como agente gerador de qualidade no ensino da Comunicação Social”.

A hipótese levantada e comprovada evidenciou que houve uma mudança nas estratégias didáticas dos cursos de graduação, atribuindo maior atenção aos estudos aplicados, ou seja, àqueles desenvolvidos nos laboratórios, familiarizando os futuros profissionais com as rotinas vigentes no mercado e procurando inoválas. Avaliando o primeiro quinquênio da EXPOCOM, Tarsitano observou que "as instituições de ensino que dela participaram apresentaram uma sensível evolução da sua qualidade, perceptível nos trabalhos inscritos". Argumentou que a competitividade instaurada pela premiação dos melhores trabalhos, diretriz que plasmava o espírito inicial da exposição e do concurso, motivara as escolas de Comunicação a supervisionar melhor os trabalhos inscritos pelos respectivos alunos, tanto no "conteúdo quanto na fundamentação teórica”.

Avaliando a iniciativa, na mesma conjuntura, o coordenador local do congresso INTERCOM 1997, Prof. Rafael Souza Silva (PUC-Santos), endossou a providência tomada pela vanguarda da nossa associação. "A inscrição de 600 trabalhos na IV EXPOCOM demonstrou o crescente interesse do alunado da graduação em participar e aperfeiçoar seus conhecimentos" (Revista Brasileira de Ciências da Comunicação. v. XX, n. 2, p.180).

Se, no início, a EXPOCOM ficava restrita à exposição dos trabalhos selecionados para visita dos congressistas e julgamento 
por parte de um júri misto, constituído por acadêmicos e profissionais, a partir de 2001 sua estrutura passou a incluir um simpósio acadêmico, destinado a debater os "avanços metodológicos”, os "conceitos" e as "categorias" empregados nos laboratórios geradores dos produtos inscritos pelos participantes (MARQUES DE MELO, 2003, p.227).

Mas o gigantismo do evento, decorrente do volume de trabalhos inscritos, a exacerbação de ânimos criada junto aos estudantes de graduação, pela natureza competitiva da mostra, bem como a "euforia" mercadológica provocada pela "premiação" junto aos mantenedores das escolas, constituíram sintomas não ignorados pelos conselhos superiores da INTERCOM. Por isso mesmo, o balanço do primeiro decênio do projeto conduziu à decisão de redimensionar sua estrutura, "em função de duas variáveis: incluir essa atividade na era digital e atualizar o sistema taxonômico vigente para torná-lo mais transparente, consensual e operativo" (MARQUES DE MELO; QUEIROZ - Unidade e diversidade na Comunicação, São Paulo, INTERCOM, 2008, p.29).

Além de regionalizar o processo de seleção e de informatizar o processo de inscrições, foram instituídas categorias taxonômicas e critérios decisórios, de acordo com os seguintes objetivos:

a) Estimular o desenvolvimento e o aprimoramento da pesquisa experimental nos cursos de graduação;

b) Promover o intercâmbio entre as escolas de Comunicação, professores e estudantes;

c) Apresentar à comunidade acadêmica nacional a produção dos cursos de Comunicação social no que se refere à área laboratorial das respectivas habilitações;

d) Apresentar ao mercado os novos talentos das diversas habilitações de Comunicação: jovens, de norte a sul, de leste a oeste, com idéias criativas, ousadas e viáveis, verdadeiros protagonistas de uma sociedade que começa a entrar em sua maturidade.

Durante o recente congresso realizado na cidade do Recife, de 2 a 6 de setembro de 2011, transcorreu a XVIII Jornada da Pes- 
quisa Experimental em Comunicação. Ali foram apresentados 301 trabalhos pré-selecionados pelos congressos regionais. Efetuados, durante o primeiro semestre de 2011, esses encontros avaliaram os trabalhos inscritos pelas respectivas escolas de Comunicação, que selecionaram previamente os melhores projetos desenvolvidos ao longo do ano letivo 2010. Cada instituição teve o direito de inscrever apenas um trabalho em cada uma das modalidades componentes das cinco categorias comunicacionais que correspondem aos cursos de graduação existentes nas universidades nacionais: 1 Cinema e Audiovisual, 2. Produção Editorial e Transdisciplinar, 3. Jornalismo, 4. Relações Públicas, 5. Publicidade e Propaganda.

A última atividade do congresso INTERCOM, em Recife, na tarde de 6 de setembro, foi inteiramente dedicada ao anúncio dos vencedores dos troféus EXPOCOM 2011, atribuídos aos melhores trabalhos produzidos durante o ano passado. $O$ principal auditório da Universidade Católica de Pernambuco foi reservado exclusivamente para acolher as delegações procedentes de todos os Estados que foram pré-selecionados nas cinco regiões geopolíticas do país: Norte, Nordeste, Centro-Oeste, Sudeste e Sul. Estudantes e professores ocuparam todos os lugares disponíveis para conhecer o veredicto do Júri Nacional que classificou os melhores trabalhos nos três dias do congresso.

\section{Indicadores e tendências}

A festa foi planejada em seus mínimos detalhes pela equipe comandada pela vice-presidente da INTERCOM, professora Nélia del Bianco (UnB). Coube ao Reitor da UNICAP, Padre Pedro Rubens e ao Presidente da INTERCOM, professor Antonio Hohlfeldt, fazer a entrega dos primeiros troféus aos estudantes vencedores.

Foram premiados 70 trabalhos, cabendo às regiões Sudeste e Nordeste o maior número de troféus (24 cada). A seguir, estão: Sul (11), Norte (7) e Centro-oeste (4).

São Paulo catalisou 13 estudos premiados, assim distribuídos: Universidade Cruzeiro do Sul - Filme não ficcional e Radionovela; Centro Universitário Belas Artes - Pesquisa de opinião e Assessoria governamental; Faculdades Integradas Rio Branco - Pesquisa labora- 
torial de TV e Jornalismo Utilitário; Faculdade Cásper Líbero - Assessoria ao Terceiro Setor; UNESP - Bauru - Organização de evento; Anhanguera de Santa Bárbara do Oeste - Fotografia publicitária; PUC-SP - Campanha publicitária; Centro Universitário Barão de Mauá - Jornal impresso; Universidade de Sorocaba - Documentário em áudio e UNITAU - Jornalismo Interpretativo.

Note-se que as vencedoras em 2011 foram instituições consideradas periféricas, na capital ou no interior, quase sempre escolas de pequeno ou médio porte, tomando o lugar antes ocupado pelas universidades tradicionais. Desse grupo, somente a Casper Líbero permaneceu em evidência, mesmo assim conquistando apenas um troféu.

Da região sudeste, além dos 13 trabalhos premiados em São Paulo, 10 troféus foram destinados a Minas Gerais e um ao Rio de Janeiro.

A região Sul contemplou 11 trabalhos premiados. Desses, seis estão ancorados no Rio Grande do Sul, três no Paraná e dois em Santa Catarina.

No espaço nordestino, os 24 troféus foram assim distribuídos. $\mathrm{Na}$ dianteira: Ceará (oito troféus), Rio Grande do Norte (seis) e Pernambuco (cinco). Na retaguarda, ficaram o Maranhão (2 troféus), além de Alagoas, Bahia e Paraíba, cada um embolsando um troféu.

As regiões Norte e Centro-Oeste pouco a pouco vão conquistando presença no cenário nacional. No Norte, a primazia cabe ao Pará, detentor de cinco prêmios, ficando o Amazonas e Rondônia com um, cada, dos sete troféus atribuídos pelo Júri Nacional. No Centro-oeste, dos quatro prêmios atribuídos, dois ficaram em Goiás e dois em Mato Grosso.

No que tange às instituições, verifica-se uma maior equidade na decisão do Júri nacional, contemplando quase meia centena de unidades de ensino superior, o que reflete a competitividade saudável instaurada em função da transparência normativa. Mas algumas se destacaram pela acumulação de maior número de troféus. Entre as universidades públicas, as mais aquinhoadas foram a UFRN (quatro prêmios) e a UFPA (quatro prêmios); entre as universidades privadas, a prevalência coube à UNICAP (três 
prêmios) e à UNIFOR (três prêmios). Sintomático é que todas elas pertencem a regiões antes pouco destacadas nas premiações da EXPOCOM.

Surpreendente também é o protagonismo que começa a ser alcançado por instituições recentes ou distantes dos centros hegemônicos, como são os casos da Faculdade Boas Novas (Manaus) - prêmio de melhor portal; Faculdade Tiradentes de Alagoas - prêmio de melhor ensaio fotográfico; Faculdade Maringá (PR) - prêmio de melhor fotografia artística; Faculdade Interamericana de Porto Velho (RO) - prêmio de melhor campanha promocional; Instituto de Educação Superior da Paraíba - prêmio de melhor publicidade digital; Faculdade do Vale do Ipojuca (PE) - prêmio de melhor livro reportagem.

Essa tendência merece uma reflexão profunda por parte dos dirigentes das grandes escolas, que não raro fortalecem rotinas burocráticas embutidas nos projetos pedagógicos dos cursos, inibindo a liberdade de criação dos docentes e engessando a inovatividade dos discentes. Suas produções laboratoriais podem parecer modernas ou avançadas, mas no fundo constituem reproduções de produtos midiáticos sem alma, dialogando com o passado e o presente, sem captar os sinais do futuro. Pobres de inventividade, acomodam-se com a mesmice institucionalizada. E começam a ser ultrapassadas pelas escolas novas: ágeis, flexíveis, cheias de vida...

\section{Conclusão preliminar}

Os indicadores anotados sugerem inúmeras reflexões, a serem amadurecidas, debatidas, analisadas.

De qualquer maneira, o espaço hoje ocupado pela EXPOCOM, nos congressos da INTERCOM, representa uma conquista que deve ser preservada, melhorada, incentivada. Trata-se de marca inconfundível da identidade brasileira no campo da pedagogia da Comunicação, unindo ensino e pesquisa, teoria e prática, academia e mercado.

A natureza dinâmica dessa atividade pressupõe uma atenção especial da vanguarda da INTERCOM, no sentido de garantir a continuidade do evento, evitando mudanças episódicas ou casuís- 
ticas. Trata-se de fortalecer uma cultura institucional, socializando junto os docentes e estudantes normas e procedimentos, evitando que se sintam confundidos com alterações na regra do jogo, durante o processo, para solucionar conflitos tópicos ou impasses residuais. Como lembra Antonio Hohlfeldt (2011, p.94) "A consequência mais nefasta (...) é que estamos sempre começando de novo, como que redescobrindo o mundo a cada momento".

Torna-se fundamental concluir um ciclo de vigência, aplicação e avaliação das normas contidas no manual Procedimentos Intercom (Moraes, 2010, p.147-167), organizadas pela equipe liderada por Nélia del Bianco, mas incorporando as diretrizes consensuais, emanadas do grupo pioneiro, capitaneado por Paulo Rogério Tarsitano, incluindo também ideias e regras agregadas por Celso Falasci, J. B. Pinho, Fernando Almeida, Adolfo Queiroz, Robson Bastos, Sueli Mara Ferreira, Marcelo Lopes, Márcio Fernandes, bem como dos funcionários Maria do Carmo Barbosa e Genio Nascimento, entre outros.

Em outras palavras, não podemos perder de vista a historicidade dos processos, enfeitiçados pelo "presentismo", correndo o risco, em relação ao qual nos adverte Marialva Barbosa (2011, p.81): "O fato de começarmos, muitas vezes, de um novo marco zero, a cada dia", acarreta "enormes dificuldades".

O grande enigma persistente está na aferição da qualidade dos trabalhos premiados, de modo a indicar em que medida eles constituem mera reprodução do que pratica o mercado ou são experimentos inovadores, capazes de mostrar aos dirigentes empresariais o potencial criativo da universidade.

Talvez isso possa ser feito, periodicamente, por meio de ensaios produzidos pela equipe que se encontra na coordenação do evento, explicando aos participantes da EXPOCOM a lógica empregada pelos júris regionais e nacionais para premiar os melhores trabalhos. Esse relato pode ser ilustrado com peças dos produtos emblemáticos, sinalizando aos novos participantes e à comunidade em geral os avanços alcançados nos laboratórios didáticos mantidos pelas universidades e instituições congêneres.

Para colimar a atual etapa da EXPOCOM é desejável que seja preparado, para 2014, um seminário nacional "Piracicaba + 20", 
com a intenção de projetar o futuro desse segmento vital para a maturidade da comunidade acadêmica brasileira no campo das ciências da Comunicação.

Como subsídio prévio, recomenda-se a elaboração de um estudo linear, avaliando diacronicamente as diferentes implicações metodológicas e teleológicas da EXPOCOM, de modo a identificar sincronicamente eventuais lacunas não visíveis a olho nu. Isso pode ser feito com tranquilidade, no próximo biênio, envolvendo os diretores regionais, que agora passam a ser peças-chaves no aperfeiçoamento do evento.

Não resta dúvida sobre o papel catalisador exercido pela EXPOCOM na projeção da INTERCOM junto à sociedade. Induzindo os futuros pesquisadores da área a não fugir da realidade, contribui para estimular o uso da criatividade e da inventividade.

Por isso mesmo, convém não perder de vista o horizonte sinalizado por Maria Immacolata V. de Lopes: “... a pesquisa na graduação define-se como didática, porque centrada na produção da Comunicação que se realiza como trabalho sistemático de formulação de demandas de Comunicação e cultura." (..) "A pesquisa didática, ao formular as demandas propõe-se a respondê-las através de produtos concretos (...) que tanto ampliem os formatos (...) existentes no mercado como renovem o exercício profissional da Comunicação em função da pluralidade e que enriquecem a cultura e democratizam a sociedade" (Lopes, 2003, p.290).

Renovar, inovar, transformar os processos comunicacionais pode ser o ponto de partida para edificar uma sociedade livre e solidária, mas também próspera e feliz.

\section{Referências}

BARBOSA, Marialva. Intercom 2011 - Programa. Recife: UNICAP, 2011.

. A pesquisa em Comunicação no Brasil: não precisamos ter mais medo do contágio, In: BARBOSA, M. ; MORAES, O.de (Orgs.). Quem tem medo da pesquisa empírica?. São Paulo: INTERCOM, 2011. p.77-90.

BRAGA; LOPES; MARTINO. Pesquisa empírica em Comunicação. São Paulo: Paulus, 2010. 
DUVERGER, Maurice. Métodos de las ciencias sociales. Barcelona: Ariel, 1962. HOHLFELDT, Antonio. É possível a pesquisa empírica num país preconceituoso e de tradição escravista?, In: BARBOSA, M.; MORAES, O. (Orgs.). Quem tem medo da pesquisa empírica? São Paulo: INTERCOM, 2011. p. 91-104.

LAGE, Nilson. Pesquisa e realidade atual. Revista Brasileira de Ciências da Comunicação, a. 16, n.1, p. 162-170. São Paulo: INTERCOM, 1993.

LOPES, Maria Immacolata V. de. A pesquisa e o ensino nas escolas de Comunicação. In: PERUZZO, Cicilia M.K.; SILVA, Robson B.da (Orgs.). Retrato do ensino de Comunicação no Brasil. Taubaté: UNITAU, 2003. p. 283-294.

MARQUES DE MELO, José. Maturidade das ciências da Comunicação no Brasil. In: PERUZZO, Cicilia M.K.; SILVA, Robson B. da (Orgs.).Retrato do ensino de comunicação no Brasil, Taubaté: UNITAU, 2003, Taubaté: UNITAU, 2003. p.275-282.

. História política das ciências da comunicação. Rio Mauad, 2008.

. Comunicação social: teoria e pesquisa. Petrópolis: Vozes, 1970.

MARQUES DE MELO, José; QUEIROZ, Adolpho. Unidade e diversidade na Comunicação, Intercom, Brasil: 2005-2008. São Paulo: INTERCOM, 2008.

MORAES, Osvando de. Procedimentos Intercom. São Paulo: INTERCOM, 2010.

PAIVA, Raquel. Pesquisa em Comunicação Comunitária: há lugar para a empiria?, In: BARBOSA, M.; MORAES, O. (Orgs.). Quem tem medo da pesquisa empírica? São Paulo: INTERCOM, 2011. p. 105-122.

PERUZZO, Cicilia M.K.; MOREIRA, Sonia V.(Orgs.). 25 anos da Intercom. São Paulo: INTERCOM, 2002.

ROSSETTI, Regina. A ruptura epistemológica com o empirismo ingênuo e inovação na pesquisa empírica em Comunicação. In: BRAGA, L.; LOPES, M.I.; MARTINO, L.(Orgs). Pesquisa empírica em comunicação. São Paulo: Paulus, 2010. p. 71-86.

SOUSA Silva, Rafael. 20 anos de conquistas. Revista Brasileira de Ciências da Comunicação, a.20, n.2, p. 179-182. São Paulo: INTERCOM, 1997.

TARSITANO, Paulo R. Tese de doutorado - abstract. Comunicação \& Sociedade, n.31, p. 294-295. São Bernardo do Campo: UMESP, 1999.

. Os projetos laboratoriais no ensino de publicidade e propaganda. In: PERUZZO, Cicilia M.K.; SILVA, Robson B. da(Orgs.). Retrato do ensino de comunicação no Brasil. Taubaté: UNITAU, 2003. p. 191-204.

Recebido: 05.09.2011

Aceito: 30.10 .2011 